\title{
Learning Medical Terminology in Risk Factors for Cardiovascular Diseases Using Concept Mapping: Case University of Medicine
}

\author{
Nasser Drareni \\ Faculty of Economics, Commercial and Management Sciences, Lounici Ali University of Blida 2, Algeria
}

Received January 14, 2020; Revised March 10, 2020; Accepted March 19, 2020

Copyright $\odot 2020$ by authors, all rights reserved. Authors agree that this article remains permanently open access under the terms of the Creative Commons Attribution License 4.0 International License

\begin{abstract}
Medical English language has developed quickly over the past few years. Concept mapping (CM) is an effective tool in teaching and learning, however ,this strategy has not been evaluated among medical terminology (MT) in risk factors for cardiovascular diseases (CVD).The purpose of this study is to introduce concept mapping to improve learning medical terminology in risk factors for card iovascular diseases course, different skills and also to determine if concept mapping increases medical learners' capability to correctly interpret medical terminology in risk factors for cardiovascular diseases. Participants were fourth year medical learners $(n=100)$ from the university of medicine Algiers in Algeria; they were randomly divided into two groups of (50), one group attending the traditional programme, the other the innovative programme. Learner performance was controlled using written knowledge tests. The Learners also evaluated the suitability of the learning process using a 7-item survey. The results of this study showed that the learners gave extremely positive ratings for the innovative course. So concept mapping is a strategy that can help medical learners, with their efforts towards meaningful learning and to enhance their different reasoning and learning skills, as well as their deeper understanding of medical terminology in risk factors for cardiovascular diseases.
\end{abstract}

Keywords Learning Medical Terminology, Improve Learning Medical Terminology in Risk Factors for Cardiovascular Diseases, Concept Mapping

\section{Introduction}

The language of medicine is mainly developed from Greek and Latin $[6,70]$. Medical terminology is used in international language, and it is also necessary for effective oral communication skills with other medical personnel. Anyone who works in a healthcare setting benefits by the capability to read, understand and interpret the medical terms used in reports, abbreviations and health records [68]. It is similar to studying a foreign language, in other words, there are rules and systems which must be applied and memorization plays a remarkable part in its mastery. The meanings of medical terms change with different beginnings and endings. Additionally, medical terms can contain multiple root words, prefixes and suffixes and combining vowels. So new medical terms had to be formed [17, 23]. To understand the meaning of medical words, it is important to learn how to dissect them into their basic elements. A physician must be very precise when dictating and interpreting a medical term. According to Wilner and Feinstein-Whittaker [68] if a letter or word is misused or unintentionally changes, the result could be unnecessary tests and appointments. Hence, an unnecessary treatment or an incorrect diagnosis, prevention, prediction and management could take place. In particular, Gylys \& Masters [31] and Lysanets \& Bieliaieva [40] showed that the rules which specify how the multitude of roots, prefixes, and suffixes can be combined are generally based in Latin. Medical terminology in risk factors for cardiovascular diseases (MT of RF for CVD) prepares learners with language skills necessary for learning effective oral communication skills [68], independent use of health and medical reference materials. It includes the study of medical terms and med ical abbreviations, symbols, and Greek and Latin word part meanings taught within the context of medical terminology in risk factors for cardiovascular diseases. Learners have the opportunity to acquire skills in interpreting medical records and communications completely and logically. Learn ing scientific language and medical terminology in risk factors for cardiovascular 
diseases continue to be challenging for many learners because of its intrinsic complexity, volu me of specific and general terminology, advanced in high technologies and many fields of sciences which include the same terminology for different applications. In order to more effectively learn and apply the language of science, we propose the use of concept mapping [51]. Concept mapping is a technique that encourages learners to learn in a meaningful learning and preserve prior and new knowledge because it engages complex cognitive structures within the brain. So meaningful learning refers to the acquisition and application of new data, information and knowledge by an individual and its interrelationship with existing relevant knowledge mental structures [46, 65, 48]. The use of concept maps has spread since it was first described in the 1960s and later supported by Novak and Gowin [43] and also has been used to collect and analyze data in research with reference to teaching and learning [20].

Constructing different types of concept maps related to medical terminology in risk factors for cardiovascular diseases are especially useful in learning abstract, general concepts, specific concepts, abbreviations and conceptual topics in which there are multiple ways to interpret abstract relationships between concepts [65]. Concept mapping allows learners to draw their deeper understanding of key ideas and demonstrates their perception of relationships among them [43, 46]. Concept mapping is a powerful strategy that can assist you to create a visual representation of complex data, information and knowledge. These graphic representations of knowledge structures include major concepts, principles and terminology. Following Novak and Cañas [49, 50] who defined concept as a perceived regularity in events or objects, or records of events or objects, and propositions as statements about some object or event in the universe, either naturally constructed. According to Pinto and Zeitz [55] concept mapping facilitated the learner's talent to organize information, assessed existing knowledge gains, developed perceptions into new and prior knowledge and transferred knowledge to new experiences. In medical education, meaningful learning is now recognized as a major goal amongst medical educators [55]. Therefore, concept maps have the potential to develop meaningful learning within medical education. However, although meaningful learning through concept mapping can be significant and stimulating, it is often difficult for teachers to move away from rote learning to meaningful learning [45, 32]. In their 1978 analysis Ausubel et al., concept maps promoted a new way of thinking and learning known as constructivist epistemology [2] which was based on the idea that individuals constructed their own knowledge over time based on what they already knew. Both teachers and learners can benefit from the use of concept maps since the maps can assist in identifying and organizing the key concepts on which a learning task was based [43].
Moreover, a concept map can be thought as a visual summary of prior, current and new knowledge. In a particular development of the method, however, on the other hand, Kinchin et al. [36] have shown how it can be used to an instrument of measurement the cognitive structures that the mapper kept in mind to describe a particular topic. In general, the analysis of concept maps can detect typologies of gross knowledge structures indicative of different patterns of understanding [34].

This study aims to provide an introduction and a literature review of concept mapping as an instructional pedagogy in different sciences, and then discusses implications for medical terminology in risk factors for CVD as tool to improve meaningful learning of the essential concepts that includes the ability to find and use appropriate learning resources and finally summarizes the findings and concludes by arguing that concept mapping has the potential to imp rove the learners' capability to learn meaningfully and resourcefully in context of medical terminology in any given situation in their careers.

\section{Materials and Methods}

The language of medicine is a specialized vocabulary used by health care providers. Deeper understanding and continuing the concepts in medicine by medical learners are among the most serious challenges they face in their careers in the future. Concept mapping is a technique that is assisting learners to construct their own useful mental structure in medical terminology of risk factors for cardiovascular diseases.

\subsection{Data Collected and Procedures}

Participants were fourth year medical learners $(n=100)$ from the University of medicine Algiers in Algeria; they were randomly divided into two groups of 50, one group attending the traditional programme, the other the innovative programme. Learner performance was measured using written knowledge tests (with a maximu m score of 20). The learners also evaluated the relevance of the learning process using a 7-item survey. Learners were encouraged to construct their own visual representations of concept maps in medical terminology. During the application activities, teacher (instructors and experts) accessed each individual's and team's map drawing to guide learner critical thinking, problem solving, mean ingful learning, deeper understanding. Learners could also type responses back to the teacher. Time was reserved at the end of class to examine various solutions yielded by individuals and teams. Throughout the interrogation, the teacher exhibits each individual's and team's map drawing using sheets of paper or any software to assess their prior, new knowledge and as sist themto create new knowledge in any given situation in medical terminology using different 
types, levels and propositions of concept maps.

\subsection{Concept Maps in Medical Terminology of Risk Factors for Cardiovascular Diseases}

Obviously, based on different researches, one strategy that can lead to meaningful learning is concept mapping. In particular, Novak and Cañas [52] suggested that the starting point should be a domain that is familiar to the learners and that this is best constructed as a focus question. In this way, in order to have skilled physicians, there is a need to prepare medical learners in ways to become life-long and meaningful learners in MT of RF for CVD. So the first step in constructing a concept map is finding a domain of knowledge. Then the learner also should define a context in which the map will be constructed. In this way, a focus question that specifies a particular problem or a question should be considered. This will show the context and the hierarchical structure of the concept maps. And the last step will be the determination of general and specific key concepts that apply to the domain knowledge and classify them from most general at the top to lower general at the bottom. By the same taken, the most specific, lower general concepts are placed either. However, Cañas et al. [16] noted variations in the degree of freedo $m$ that learners have in developing a concept map. During the application activities, learners are able to externalize their original knowledge and incorporate it with new one for rearranging and internalizing both the old and new knowledge [27, 18].

Through these application activities, learners were directed to build many different concept maps related to medical terminology in RF for CVD in which they needed to use 20 concepts pulled from topics directed in the fundamental module and the process of learning and teaching and showed how they relate to one another with different types of levels such as one level (figure 1), two levels, multiple levels, network levels and interdisciplinary levels (figures 2, 3). They could use any of the chosen topics as their beginning topic for the concept maps, such as ischaemia and arrhythmia, which they were just given for their individuals and groups concept maps. They were given a large piece of paper, such as from a flip chart, and were ordered they could add more sheets of paper if needed (figures 1, 2, 3). Following, Betty [7]; Betsy [8]; Carol [15] and Gylys \& Masters [31] learners were also ordered they could add any additional topics from the module, but at a minimu $\mathrm{m}$, they needed to use the 20 concepts and learners were given 90 minutes to work. By the end of these application activities using several concept maps which consist of different types related to MT in RF for CVD, learners becoming familiar with medical terminology in CVD is like learning a new language, however, you can figure out the meaning of many different words just by analyzing the word parts using different concept mapping process demonstrates what learners see as important concepts and how they relate these concepts.

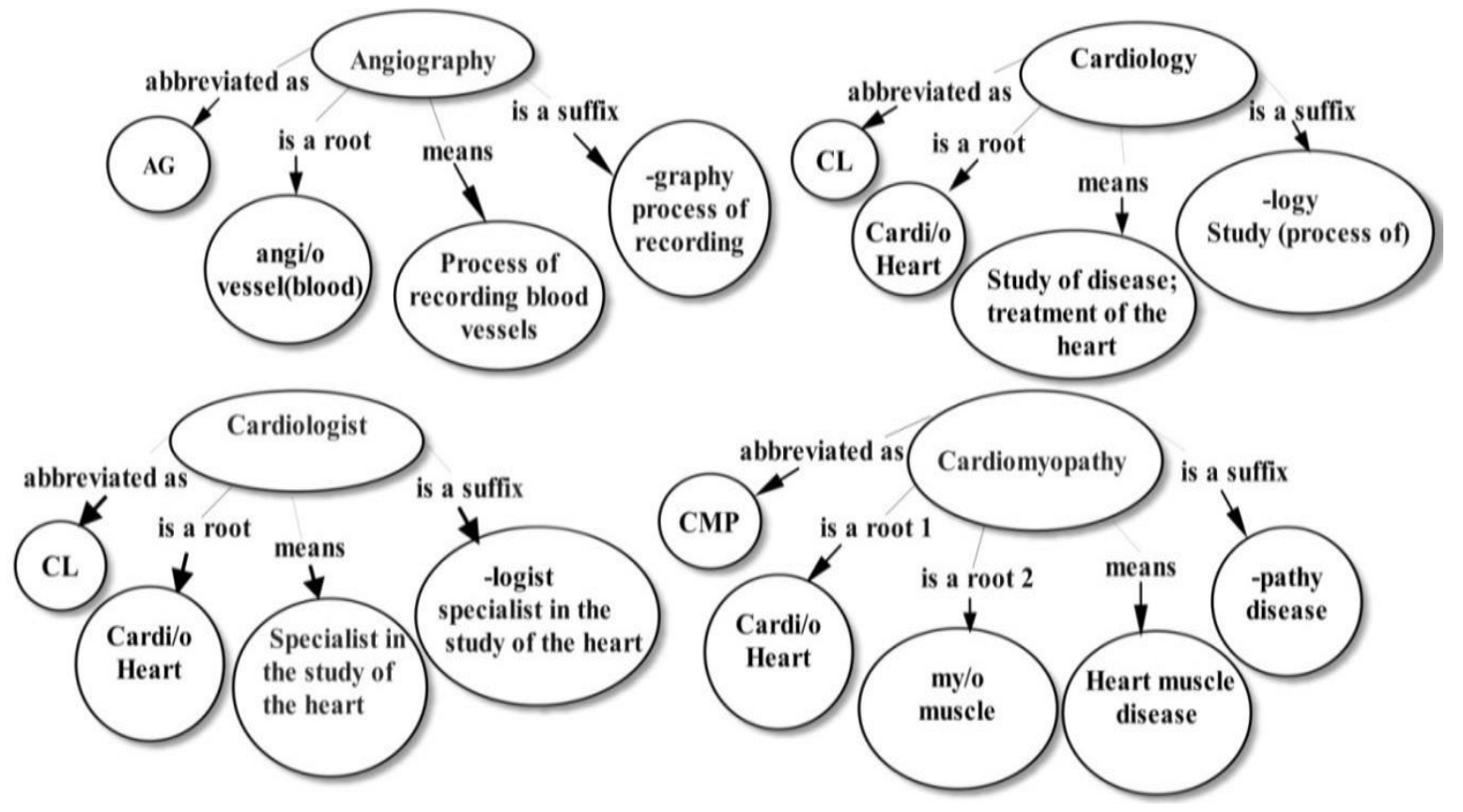

Figure 1. List of given concept maps of one level in risk factors for cardiovascular diseases 


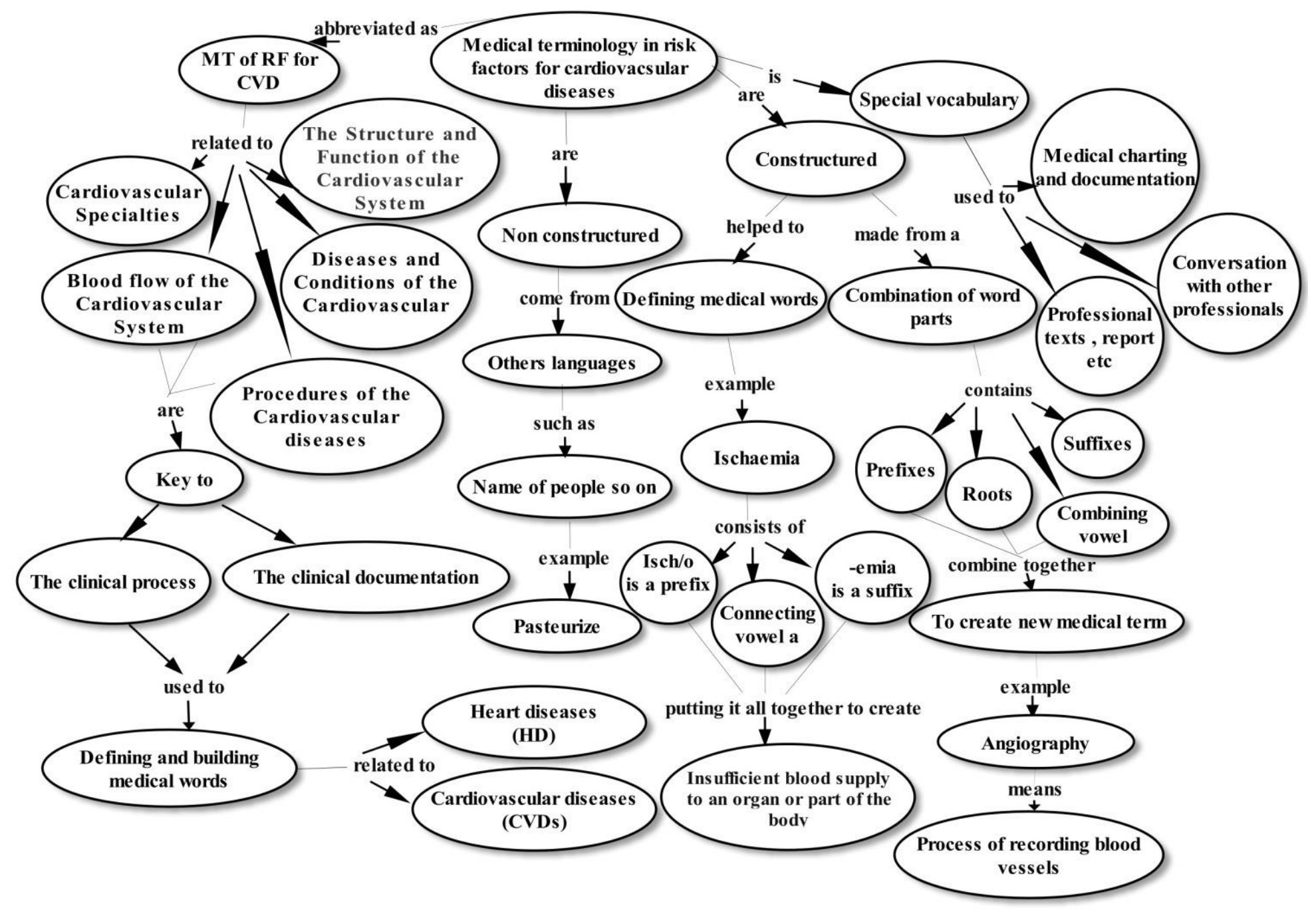

Figure 2. Concept maps of the structure of medical terminology in risk factors for cardiovascular diseases 


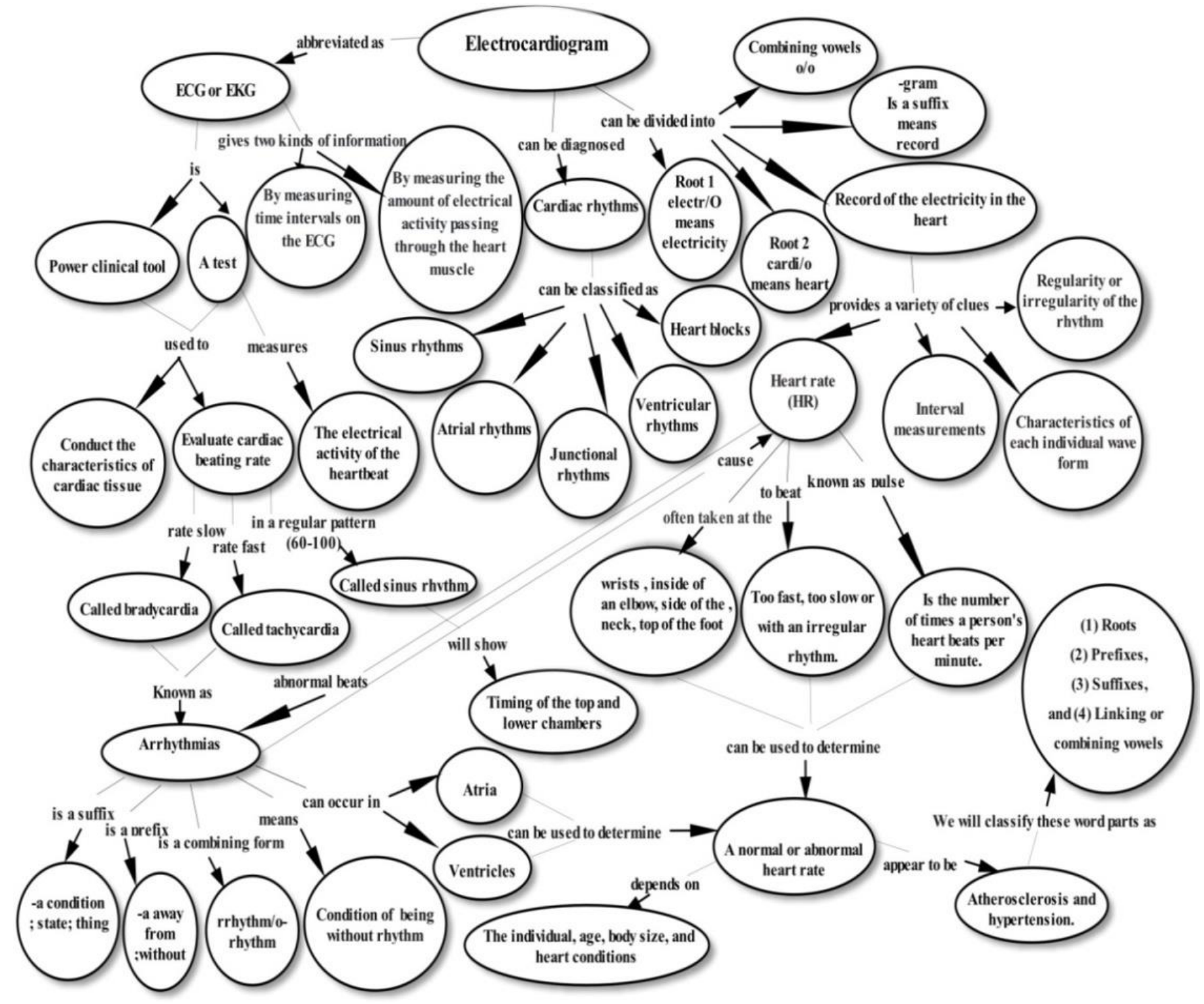

Figure 3. Concept maps of the structure of electrocardigram in risk factors for cardiovascular diseases 
Table 1. Procedure of application activities using concept maps in medical terminology of risk factors for cardiovascular diseases

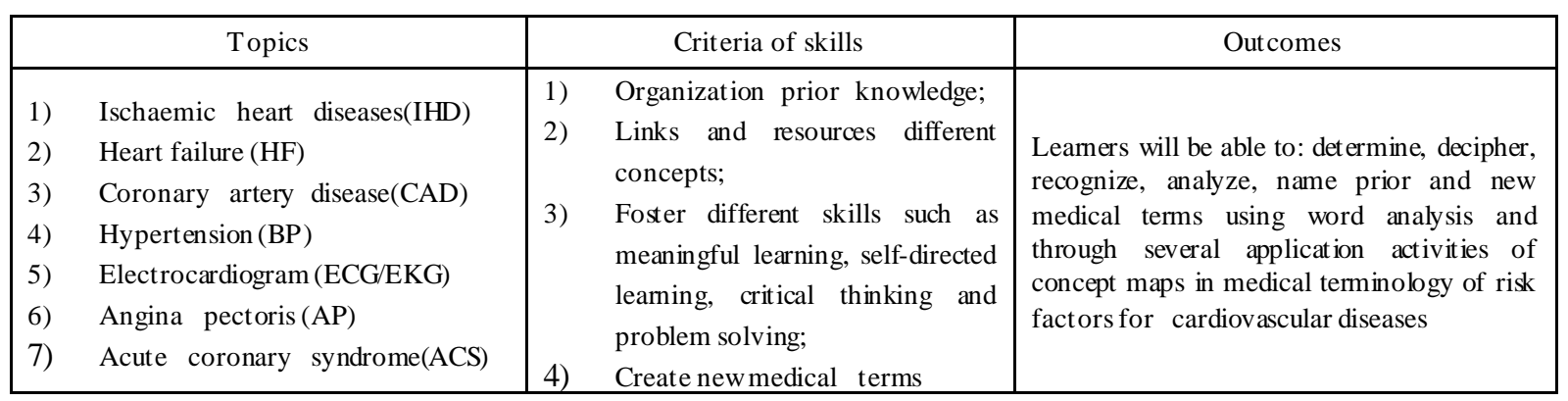

\subsubsection{Concept Maps as a Teacher Tool in Medical} Terminology of Risk Factors for Cardiovascular Diseases

According to Gylys and Masters [31] who showed, for example, arrhythmia and dysrhythmia these two medical terms connecting to the abnormal rhyth $m$ of the heart rate are very similar in their meanings, but they have extremely important differences. As you have taught, the prefix (a-) means without, absence of, and the prefix (dys-) means bad, abnormal, painful and difficult. Then look closely at the word roots. They are not similar. The medical term arrhythmia (condition of without rhythm) has an additional (r). To reme mber which medical term is spelt with two (rs), it might help to think of the expression (without rhyme or reason). A condition of arrhythmia is a heartbeat (without rhyme or reason), whereas a condition of dysrhythmia is a heartbeat with an abnormal rhythm. Arrhythmia is used much more often than dysrhythmia. Moreover, learners need this medical terminology because the heart is the most important organ in the body and essential to the continued functioning of the body. Following, Betty [7]; Betsy [8] and Carol [15] illustrated an example of a concept map that described the structure of MT in RF for CVD using different topics and application activities directed in the fundamental module (figure 2, table 1), the concepts are represented in a hierarchical style. Overall, medical learners had more comments that concept mapping application activities we re helpful for immediate feedback and exam preparation and fewer comments about maps being more busy work and difficult challenges.

\subsubsection{Concept Maps as a Learner Tool in Medical Terminology of Risk Factors for Cardiovascular Diseases}

These application activities were organized during the last lecture of the module; two lectures after the learners completed a multiple choice with 100 questions test on all aspects of the MT of RF for CVD. The participants were Algerian learners $(n=100)$, studying in the field of medical education, pharmacy and dental surgery from the university of medicine A lgiers, A lgeria. All of them, at the time of the study, were fourth year learners and were randomly chosen to participate in this study. The learners were randomly divided into two groups. Group one $(n=50)$ was taught to use concept maps to learn medical terminology related to risk factors for CVD, while group two $(n=50)$ was taught by traditional approaches.

The methodology used to assess the level of the learning process in the MT in RF for CVD module is composed of four steps as follows:

\section{First step: A deeper understanding}

Learners were introduced to the knowledge of MT in RF for CVD and concept mapping and its practical applications from theoretical, practical, clinical and laboratory reasoning and through several examples during their class sessions.

\section{Second step: Constructing concept maps}

Afterwards, a question-answer session. Then, the learners were asked to prepare a concept map of their understanding of MT in RF for CVD module. For their assistance with the activities, learners were asked to use a variety of questions, for example: What is an MT in RF for CVD? Where are they used? How they are developed? Why are they important? How they are formed? How they are deciphered? and the learners were given 30 minutes to construct their own maps on paper or using any software. The built concept maps were then gathered and classified depending on learners' origin and level of prior experience.

Third step: Assessment of the learning process using a 7-item survey

The learners also evaluated the suitability of the learning process using a 7-item survey. Each group was attributed with facilitators (Instructors and experts) fro m all the three departments: medicine, pharmacy and dental surgery for coordination and to guide the learners for making their distributed topics related concept maps. All the concept maps prepared by the individuals and small groups were judged by senior faculty members of other disciplines. Prior knowledge about the topics was already informed to all the judges.

Finally, the fourth step: Learners as ses sed using the rubric of criteria

Learners assessed all the maps as individuals and groups based on the given criteria such as 1). Abilities to organize 
their prior and new knowledge; 2). Connect and resource different concepts; 3). Foster skills such as meaningful learning, self-directed learning, critical thinking and problem solving skills; 4). Capabilities to construct new medical terms with their meanings.

Following, Dzuganova [21]; Betty [7]; Betsy [8]; Carol [15]; Dong et al. [22] and Drareni [24] represented a map of the structure of electrocardiogram (figure 3, ECG/EKG). In figure 3 above illustrated an example of a concept map that described the structure of electrocardiogram using different topics and application activities directed in the fundamental module, the concepts are represented in a hierarchical style. of course, from the map, as findings shown that the experimental group boosted importantly more than control group to create new medical terms from the word parts connected with the electrocardiogram, to explain, pronounce and spell the word parts used to create new medical terms for the electrocardiogram and to decipher, dissect and describe common medical terms used for symptoms, diseases, disorders, procedures ,treatments, prediction, prevention, management and devices connected with the cardiovascular diseases. In addition, Betsy [8] and Carol [15] indicated the huge essential of differentiating between medical terms in CVD, for example, echocardiography and electrocardiography are both tools of measuring heart function. The two medical terms are similar enough in construction and in meaning to be confusing. Let the word parts supply the clue of information that helps learners to identify and give a meaning of new medical terms. Remember that one hears an echo, and thus, echocardiography is the procedure that uses ultrasound (US) technology to make measure ments of heart function. Learning medical terminology in risk factors for CVD is like to learn a foreign language. We summed up that using an expert concept mapping as an advanced organizer progresses knowledge organization $[1,2]$ and integration as well as enhancing deeper understanding, meaningful learning and self-directed learning of medical terms in risk factors for cardiovascular diseases.

\subsubsection{Concept Maps as an Assessment Toolin Medical Terminology of Risk Factors for Cardiovascular Diseases}

After the learning and practicing phases, learners from both of group one and group two were asked to construct their own concept maps as individuals and groups in an hour using different application activities with different maps to resolve the most proble mat ic with medical terms in
CVD. Learners need prior and new knowledge of how the medical terms are formed. At the first stage, the topics selected were distributed to the small groups and details of the topics were discussed between facilitators (instructors and experts) and learners. Also, learners completed multiple choice knowledge tests which each test contained 20 questions, and questions were based on the topic given to each group. The organizing stage included a deeper analys is of the medical terms problem related to the topic. The data, information and knowledge were listed out and integrated with the planning stage. For example, the basic electrocardiogram concepts were connected to the clinical problems in linkage stage. Revising of the existing knowledge and try to obtain insights to new knowledge were done in revising and finalizing stage. There was also exchange of information and ideas amongst the learners. these application activities exhibited that concept mapping is an ideal pedagogy for meaningful learning in MT of RF for CVD. Learning in a meaningful way means that medical learners, residents, and practicing physicians actively look for ways to as sociate new information and experience with what they already know, necessarily creating an organized knowledge driving to the development of adaptive expertise in medical practice. In the same manner, in the clinical field, Cutrer et al. [14] found that resident physicians who used concept maps as an advanced by organizing performed better on an ass essment measure than the control group and concluded that concept maps improve knowledge organization. This finding also consistent with the study of Santos et al. [64] highlighted that knowledge organization was the main purpose of applying CMs in computer science. In this regard, concept mapping is a strategy that is serving learners to construct their own skilled mental structure in creating medical terms in future and to be independent, mean ingful and self-d irected learners in any given situation in their careers in the future. At the second stage, learners in group one and two were also required to organize a feedback survey at the end of the course. The survey was contained of a 7-item which were established by the teachers (table 2). It was found that the learners who used the concept maps to learn and teach MT of RF for CVD performed better than those who did not use the concept maps in providing arguments when deciphering the medical terms. Feedback was acquired from learners about their perception, usefulness, understanding and overall impact from a 7-item, following, Susan [61] who referred that all items were rated on a 5-point Likert scale, ranging from 1 (strongly disagree) to 5 (strongly agree). 
Table 2. Learners' responses about concept maps used in medical terminology of risk factors in cardiovascular diseases (\%)

\begin{tabular}{|l|l|c|c|c|c|c|}
\hline No & Statements & SD & D & N & A & SA \\
\hline 1 & $\begin{array}{l}\text { Concept maps were a tool to facilitate meaningful learning ,self-directed } \\
\text { learning,critical thinking and problem solving skills }\end{array}$ & $\begin{array}{c}0 \\
(0)\end{array}$ & $\begin{array}{c}0 \\
(0)\end{array}$ & $\begin{array}{c}10 \\
(10)\end{array}$ & $\begin{array}{c}5 \\
(5)\end{array}$ & $\begin{array}{c}85 \\
(85)\end{array}$ \\
\hline 2 & $\begin{array}{l}\text { Concept maps aided to define the word parts used to createnew medicalterms in risk } \\
\text { factors for cardiovascular diseases }\end{array}$ & $\begin{array}{c}0 \\
(0)\end{array}$ & $\begin{array}{c}0 \\
(0)\end{array}$ & $\begin{array}{c}16 \\
(16)\end{array}$ & $\begin{array}{c}4 \\
(4)\end{array}$ & $\begin{array}{c}80 \\
(80)\end{array}$ \\
\hline 3 & $\begin{array}{l}\text { Concept maps assisted to create new medical terms from the word parts associated } \\
\text { with the risk factors forcardiovascular diseases }\end{array}$ & $\begin{array}{c}0 \\
(0)\end{array}$ & $\begin{array}{c}0 \\
(0)\end{array}$ & $\begin{array}{c}18 \\
(18)\end{array}$ & $\begin{array}{c}2 \\
(2)\end{array}$ & $\begin{array}{c}80 \\
(80)\end{array}$ \\
\hline 4 & $\begin{array}{l}\text { Concept maps assisted to connect and resource medical terminology in risk factors } \\
\text { for cardiovascular diseases theoretical information to clinical and laboratory } \\
\text { communication skills }\end{array}$ & $\begin{array}{c}0 \\
(0)\end{array}$ & $\begin{array}{c}0 \\
(0)\end{array}$ & $\begin{array}{c}7 \\
(7)\end{array}$ & $\begin{array}{c}1 \\
(1)\end{array}$ & $\begin{array}{c}92 \\
(92)\end{array}$ \\
\hline 5 & $\begin{array}{l}\text { Concept maps helped to organizeprior knowledge and createnewknowledge } \\
(0)\end{array}$ & $\begin{array}{c}0 \\
(0)\end{array}$ & $\begin{array}{c}2 \\
(2)\end{array}$ & $\begin{array}{c}8 \\
(8)\end{array}$ & $\begin{array}{c}90 \\
(90)\end{array}$ \\
\hline 6 & $\begin{array}{l}\text { Concept maps encouraged to recognize, define and construct the medical terms } \\
\text { related to the pathology, the diagnostic and treatment procedures of the } \\
\text { cardiovascular diseases }\end{array}$ & $\begin{array}{c}0 \\
(0)\end{array}$ & $\begin{array}{c}0 \\
(0)\end{array}$ & $\begin{array}{c}2 \\
(2)\end{array}$ & $\begin{array}{c}5 \\
(5)\end{array}$ & $\begin{array}{c}93 \\
(93)\end{array}$ \\
\hline 7 & $\begin{array}{l}\text { Would you continue to use concept mapsto solve problem in medical terminology in } \\
\text { risk factors for cardiovascular diseases in the future }\end{array}$ & $\begin{array}{c}0 \\
(0)\end{array}$ & $\begin{array}{c}0 \\
(0)\end{array}$ & $\begin{array}{c}0 \\
(0)\end{array}$ & $\begin{array}{c}0 \\
(0)\end{array}$ & $\begin{array}{c}100 \\
(100)\end{array}$ \\
\hline
\end{tabular}

Recording from learners' responses: SD strongly disagree, D disagree, $\mathrm{N}$ neutral, A agree, SA strongly agree. The answers were recorded on a typical five-level Likert scale ( 1 = strongly disagree, $2=$ disagree, $3=$ neutral (neither Agree nor disagree), $4=$ agree, $5=$ strongly agree). ( ):

Numbers in parentheses indicate the number of learners answers

\section{Results and Discussion}

The findings of using concept maps as individuals and groups have provided a meaningful learning tool, critical thinking and problem-solving skills necessary to pull together the relevant and related concepts in medical terminology in risk factors for CVD in any given context in the future (appendices). These findings are consistent with learners' responses and previous studies $[44,4,13,39,24$, 25].

\subsection{Results}

The results signalled that the concept maps could facilitate learners' ill-structured problem solving related to MT of RF for CVD which facilitates effective oral communication skills and correspondence between physicians across borders and from different parts of the world (appendix 2). The learners' responses to the satisfaction survey seemed that most of them agreed that $\mathrm{CM}$ encouraged them to learn and understand medical terminology in RF for CVD course, also included and demonstrated the inter-relationships among topics content of CVD module (appendix 1). Furthermore, most of the learners confirmed that $\mathrm{CM}$ motivated them to learn and to think independently and critically so to become more self-directed learning, meaningful learning and critical thinking $(85 \%)$. While $(92 \%)$ felt that concept maps made them a critical thinker as it motivated effective oral communication skills, also this is what has been proved by Atay and Karabacak [4] who argued that the experimental group had developed better critical thinking skills than the control group. This was supported by Chabeli [13]; Ku mar [37] and Kaddoura [39] who found in their study that learners had extremely positive opinion regarding using concept maps and they have expressed that if they are taught to use concept maps fro $m$ the first year, it will be one of the best methods to learn. Most of the learners (80\%) believed that concept maps were helpful to recognize the word parts used to create new medical terms and on other hands, to enhance their deeper understanding of the topic in MT of RF for CVD [24, 25]. Amongst all 100 learners $(90 \%)$, strongly felt that concept maps were helpful to organize prior knowledge and create new knowledge to learn medical terminology using word parts associated with the RF for CVD and (93\%) learners strongly agreed that concept maps were helpful to solve complex problem in learning $\mathrm{MT}$ in $\mathrm{RF}$ for $\mathrm{CVD}$ and will be able to communicate clearly about their patients. However, a considerable majority of learners $(100 \%)$ showed that they would continue using concept maps to solve more complex problems in learning medical terminology in the future because learners look at it as like speaking a foreign language and is vital to prevent errors at all stages of care diagnosis, prevention, management and treatment. according to qualitative analysis (table 2), majority of learners extremely accepted concept maps as a helpful tool to foster meaningful, self-directed learning, advance critical thinking and problem solving skills. Finally, difficult challenges to learn and to teach at the starting and time consuming are the two problems in using this technique in learning and teaching MT in RF for CVD, nonetheless, the overwhelming majority of the learners extremely signalled to continue using it.

\subsection{Discussion and Limitation}

The findings of this study have provided a qualitative (appendix 2 and appendix 3) and a quantitative (table 2, appendix 3 and appendix 4) vie wpoint of concluding that CM can be applied in other subject-matter do mains, such as MT in RF for CVD. The results are divided into two elements $[5,3,30]$. The first element is that concept maps are as a useful tool, as they advance learners' meaningful 
learning, critical thinking, problem solving skills and engagement through individuals and groups $\mathrm{CM}_{\mathrm{s}}$ discussion. These findings are consistent with previous studies, which have shown that utilizing concept maps in medical education supplies more opportunities for all learners to actively participate in class application activities, hence developing their capability to identify relationships among the key concepts within a given discipline Rendas et al. [58] ; Hay et al. [34] and Drareni $[24,25]$. The second element is that concept maps are effective in helping learners understand the topic matter, therefore clarifying initial misconceptions [34]. In accordance with previous studies, functioning prior knowledge is an essential condition to help learners learn deeply and meaningfully [34]. On the same manner, this stresses that the role of the teacher in the process of constructing maps is most important to securing the learners' long-term learning success [30]. These findings were consistent with Ellermann et al. [26]; Sharma [63] and KumarManoj \& Rizwaan [38] who highlighted that CM teaching method is based on meaningful learning, and learning occurs when the learners were able to organize and relate the concepts and new information with their mental structures. This was also agreed by Chularut \& DeBacker [10] and Yaowalak [69] who stated that CM is considered as a good strategy to encourage learners' learning in a higher education setting in the UK, USA and Taiwan. To sum up, most of the experimental learners perceived CM conclusively and teachers documented that the development of concept maps in groups aided learner learning in relation to the contents of MT in RF for CVD and fostered their meaningful learning in several other ways. In this way, effective oral communication skills, critical thin king and problem solving skills as a foundation for other meaningful learning activities can be increased and designed. Like wise, Cutrer et al. [14] who assured that using concept maps are a considerable strategy for meaningful learning. Learners can analysis and arrange existing prior knowledge, organize new knowledge, recognize a new component of a concept or idea, and relate former and create new knowledge in MT of RF for CVD.

Finally, the central advantage of concept mapping is precisely its relational achievement. As described above, concept maps empower relational links to be made between pertinent general and specific concepts. In the instructional context, it is insisted that meaningful learning best took place by linking new concepts to existing knowledge [41]. Hence, Maas and Leauby [41] stated that concept maps empowered the elements of learning to connect to how cognitive knowledge is developed structurally by the learner. a major disadvantage of concept mapping is that it is limited to relations between general and specific concepts. So many issues in MT of RF for CVD require more than a determination of relationships between concepts $[28,29]$ who created a biology network revealed 67 relations used to link about 2,300 concepts and also in a network of about 70 propositions. Also, the difficulty in linking phrases and lack of carefu lness in concept mapping are already reported by other researchers [12]. On the other hand, Sowa [60]; Kremer, [35] and Sowa [61] documented that concept maps in the field of artificial intelligence (AI) community are considered as non-rigorous in methodology, and the maps lack in knowledge representation (KR) formalis ms. This point of critique is cited in the works of Kremer [31] and Cañas \& Carvalho [41] showed that concept maps and artificial intelligence (AI) or knowledge representation (KR) was not compatible. This is a limitation of concept mapping and it has led to the development of a new kind of $\mathrm{CM}$; a $\mathrm{CM}$ for interdisciplinary maps that demands identification of relationships between concepts and interdisciplinary perspectives in medical terminology for CVD. Correspondingly, these findings were inconsistent with Oppl and Stary [54] who highlighted that the healthcare case demonstrated how meaningful work-model entities evolve in the course of articulation and guide aligned restructuring of work, by showing supporters to achieve major objectives of progressive education and conceptualized a learn ing env iron ment providing learning facilities. Also, these authors concluded that active exploring of problems boosted analytical thinking, creativity, practical abilities, and social capabilities for problem solving, since learning should also happen in groups so concept maps are an effective tool for improving learners' capability to think critically and meaningfully.

\section{Conclusions and Recommendations}

Concept mapping can be a very powerful tool to foster a higher level of critical thinking, problem solving, mean ingfuland resourceful skills [43, 47, 67]. The findings of this study have provided a qualitative pers pective of accepting that $\mathrm{CM}$ can be applied in other domains, such as medical terminology in risk factors for CVD so we can believe that concept mapping aids learners to grow their deeper knowledge in an accumulative process and enhances the required critical thinking, problem solving skills and practical competencies that a medical learner needs in their career in the future. These results are consistent with those found by Novak \& Canas $[49,50]$ and Kumar et al. [37]. Finally, the use of concept maps in learning medical terminology related to RF for CVD make the idea of the development and the training of learners' independence, since self-d irected learning, critical thinking and problem solving skills are the es sential factors to make meaningful learning then will be able to construct their own effective oral communication skills that are necessary between physicians-patients. On the other hand, according to Baig M. et al. [9] stated that concept map is leading to retention of learning conceptual knowledge with an 
improved deeper understanding of the concepts, retention of useful knowledge and improvement in the performance of medical learners.

Further, this study suggested that a lack of medical knowledge in technical terms, interpreting enormous health data and communicating effectively with physicians-patients and other health professionals should address in medical terminology of effective oral communication skills that can be taught to medical learners to increase their clinical, practical and laboratory reasoning skills using more than innovative methods such as CM alone and mixed it with other active learning such as problem-based and team-based learning to enhance their mean ingful learning, critical thinking and problem solving skills. A lso, the findings of this study recommended using other types of $\mathrm{CM}_{\mathrm{s}}$ such as knowledge concept maps and collaborative concept maps by experts which used to preserve organizational knowledge that have been associated with meaningful learning theory and promotion of higher order thinking skills $[59,19]$.

\section{Acknowledgements}

The author would like to thank the participants and expert reviewers that have contributed to the development of the guideline.

\section{Funding Statement}

This research did not receive any specific grant from funding agencies in the public, commercial, or not-for-profit sectors.

\section{Appendices}

\section{Appendix 1. Procedures and Conceptual Framework of Application Activities}

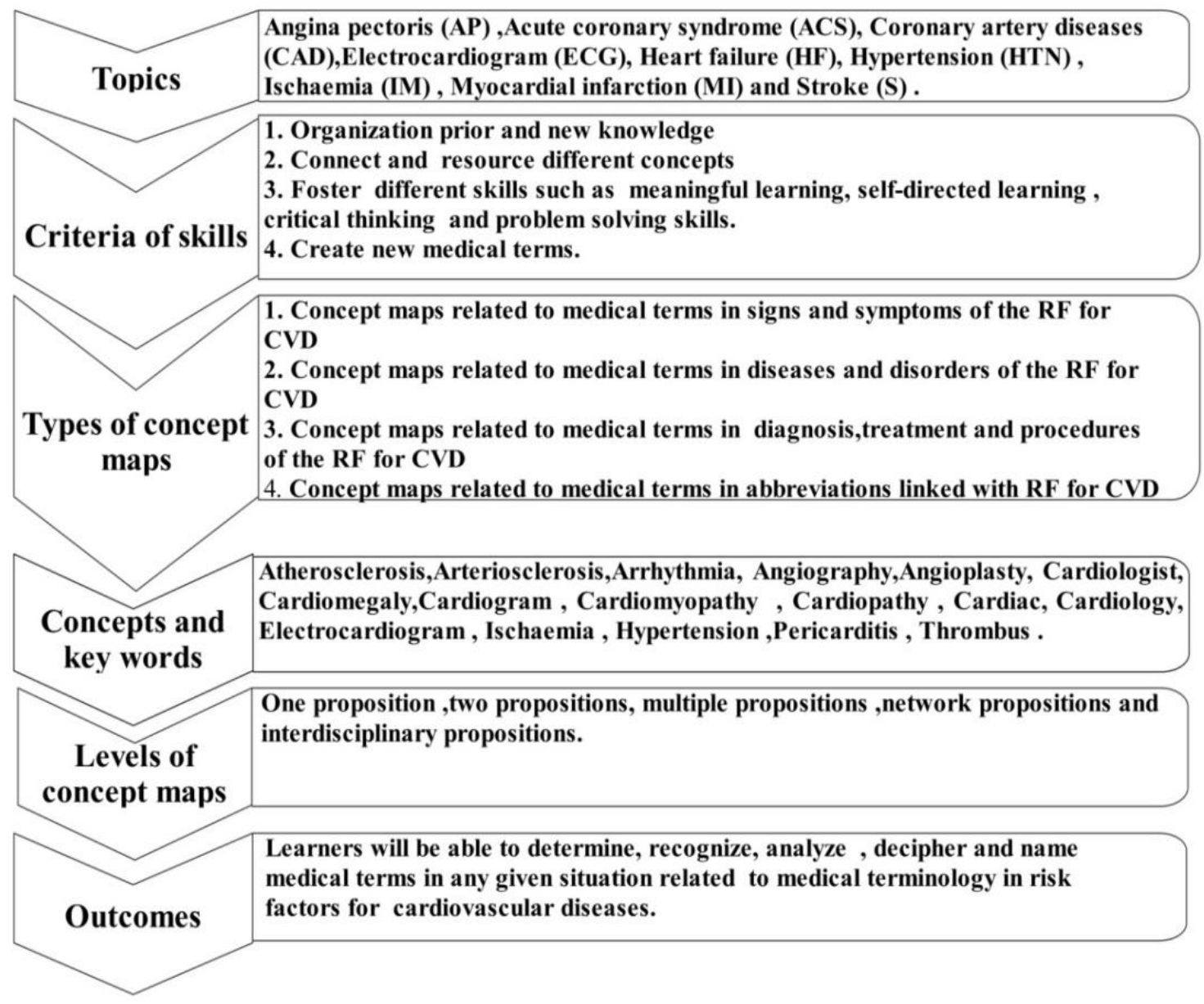

Figure 4. Phases of application activities procedures using concept maps 


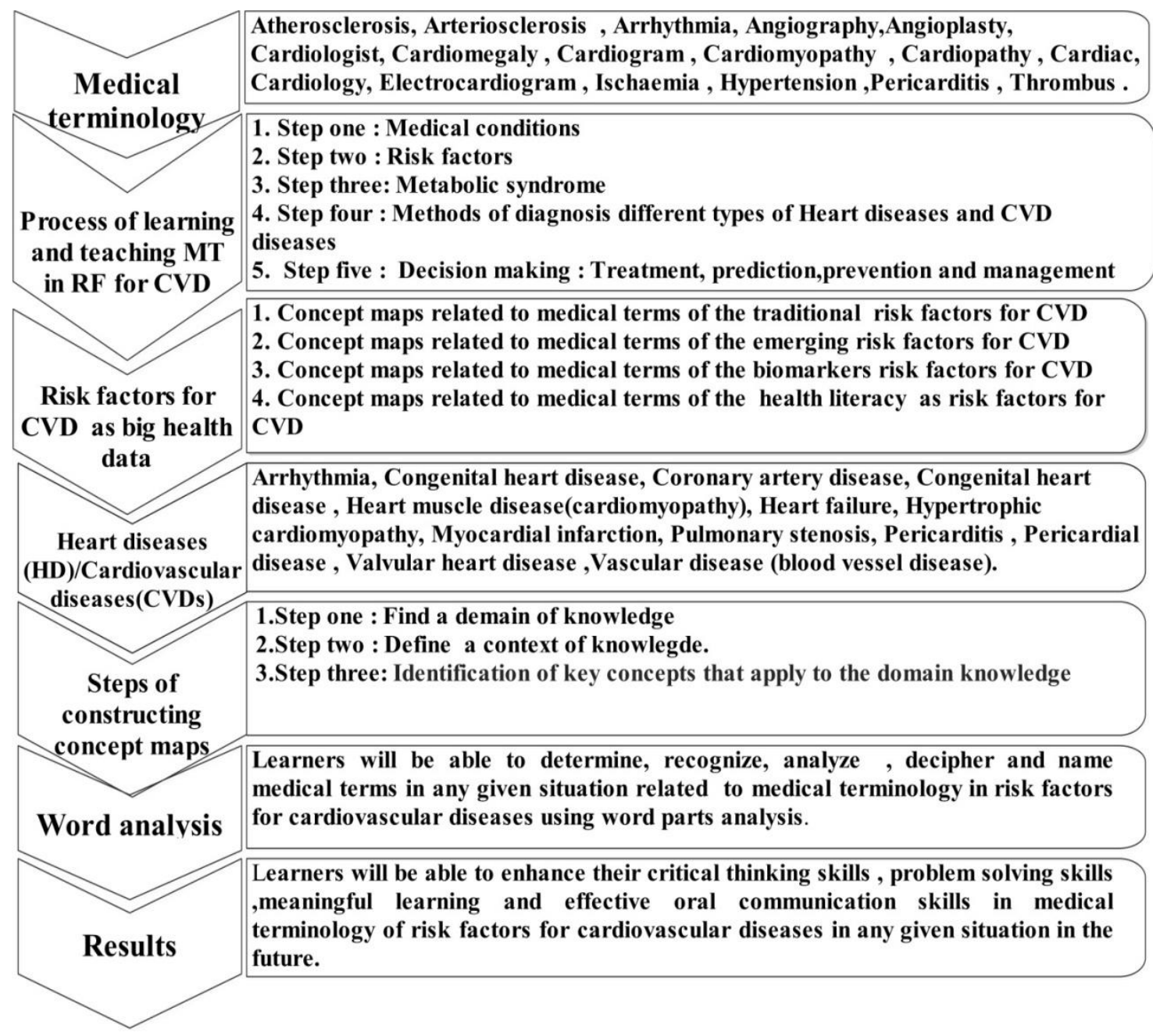

Figure 5. Conceptual framework of application activities using concept maps

Appendix 2. Sessions of Constructing Concept Maps Based on Different Medical Resources

- Learners should be able to construct their own different levels and propositions of concept maps based on a medical terms text, medical terms reports and medical terms case studies in medical terminology of risk factors for CVD.

- Learners should be able to enhance the learning to learn meaningfully and critically.

- Learners should be able to develop the learners' graphic capabilities and creativity to organize their prior and new knowledge.

- $\quad$ Learners should be able to develop the capability to structure, organize, and create knowledge concept maps.

First session: constructing concept maps based on different medical resources (texts, medical reports and case studies).

Approach and steps of application activities (90 minutes)

Learners a re arranged individually to construct their own concept maps and then in small groups to create their collaborative concept maps in the classroom. The teacher (with instructors and experts) give the learners a printout of application activities, consisting of a medical terminology text in CVD, entitled medical terminology in risk factors for cardiovascular diseases, the steps for completing the activities and many blank sheets of paper to do the activities with software to draw and present their concept maps as individuals and groups.

Session to learn how to construct a concept map (16 steps)

Learners are arranged individually and then in small groups to create their individual and collaborative concept maps in the classroom according to the following steps:

\section{Step 1: Reading}

The learners read the medical terminology in risk factors for CVD from different resources such as texts, reports and case studies (from the fundamental module).

\section{Step 2: Question-answer discussion}

The learners were asked to use a variety of questions (questions-answers) related to medical terminology in risk factors for CVD. 
Step 3: Identify a domain of knowledge

The learners were asked to determine a domain of knowledge through the fundamental module.

Step 4: Identify the key ideas

The learners identify the key ideas (general and specific concepts), directed by key questions written by the teacher and also assisted by the instructors and experts.

Steps 1, 2, 3, 4 and 5: Explain the main concepts

The teacher explains the main key ideas. While the instructors and experts explain the specific key ideas of the medical terminology from other fields of medical education.

Steps 1, 2, 3, 4, 5 and 6: Show how to identify the main concepts

The Teacher/instructors/experts show how to determine the key concepts and how to construct, classify, identify and organize a list of general and specific concepts.

Steps 7: Identify the key concepts (20) and organize them

The learners identify the key concepts (20) and organize them in order of relevance (from most general at the top to most specific at the bottom).

Step 8: Place the key concepts

The learners place the concepts on a blank sheet of paper according to levels of hierarchic importance (from more general to more specific).

Step 9: Beginning of constructing the components of the maps

The learners draw labels, lines, joining the concepts using linking phrases.

Steps 8, 9 and 10: Animated by the instructors and experts

The teacher shows his/her way of positioning and joining the concepts, aided by the guided, progressive and animated by instructors and experts.

Step 11: Learners add the linking words

The learners add the linking words between the general and specific concepts, setting up relationships between them and creating propositions.

Step 12: Animated by the instructors and experts

The teacher shows his/her way of adding the key words and phrases and building propositions, assisted by the instructors and experts.

Step 13: Teacher adds cross links

The teacher adds cross links that connect the concepts belonging to different hierarchical branches of the concept map.
Step 14: Animated by the instructors and experts

The teacher shows his/her way of adding the cross links on the map, assisted by the instructors and experts.

Step 15: Animated by the instructors and experts

The instructors and experts show his/her manner of constructing knowledge concept maps in MT of RF for CVD using medical terms such as hypertension, arrhythmia and cardiopathy.

Step 16: Assessment of all maps and animated by the teacher, instructors and experts

The teacher/instructors/experts proceed to collect the maps created to evaluate them and hands out a copy of the list of key concepts and concept map he or she created based on the text and shown in the PowerPoint presentation.

Second session: session to learn how to construct new types of concept maps such as knowledge concept maps in medical terminology of risk factors for cardiovascular diseases

In this session, the learners practice what they have learned and individually develop a concept map, following the steps set out in the first session. With the help of instructors and experts, learners construct their own other types of $\mathrm{CM}_{\mathrm{s}}$ such as knowledge $\mathrm{CM}_{\mathrm{s}}$ and collaborative $\mathrm{CM}_{\mathrm{s}}$. These maps display how medical terms in risk factors are derived from medical conditions. Many learners have difficulty with the concept of medical terminology in risk factors for CVD and also show different medical terms related to diseases, conditions, and procedures related to the cardiovascular diseases (CVD) and heart diseases (HD). These maps also extend the concept of health literacy consider as modifiable risk factors for CVD. Overwhelmingly, the majority of learners need knowledge of how the medical terms in CVD are formed. Thus, at the end of the second session, learners will be able to describe the parts of words used to create medical terms, analyze medical terms to determine meaning, give the meanings of a beginning set of roots, combining forms, suffixes and prefixes, and name the referents of abbreviations; list abbreviations for various medical phrases related to :

- Signs and symptoms of the cardiovascular system

- Diseases and disorders of the cardiovascular system

- Treatments, procedures, and devices of the cardiovascular system

- Abbreviations of the cardiovascular system

- Risk factors for cardiovascular diseases

Finally, these maps provide a meaningful learning tool, critical thinking and problem solving skills necessary to pull together the relevant and related concepts in medical terminology in risk factors for CVD in any given context in the future. 


\section{Appendix 3. Knowledge Tests of Medical Terminology} in RF for CVD (Sample of Choice Questions)

1. To develop a medical vocabulary, you must understand the that form medical terminology words.

2. In the medical terminology words cardiology, cardiovascular, cardiac, the word root is

3. Identify the roots in the following medical terminology in cardiovascular diseases words:

- Myocardial

- Cardiogram

- Thrombus .....

- Hyperlipidemia

4. Write the roots for each of these terms:

- Cardi/ac

- Cardi/gram

- Cardi/pathy

- Cardi/logy

- Ather/sclerosis

5. The root in cardi/o is the combining vowel is

6. The following medical terms, first write the suffix and its meaning. Then interpret the meaning of the remaining elements starting with the first part of the word.

- $\quad$ Endo/cardi/um

- Cardi/o/megaly

- Aort/o/stenosis

- Tachy/cardia

- $\quad$ Peri/cardi/tis

- Thromb/o/lysis

- Vas/o/spasm.

- Ather/oma

- Electr/o/cardi/o/graphy

7. Review the diseases of the heart and blood vessels by writing the abbreviation for the

- Heart failure:

- Acute coronary syndrome: .........

- Congenital heart disease:

- Ischaemic heart disease:

- Coronary artery diseases:

- Cardiovascular diseases:

- Heart diseases:

- Cardiopulmonary resuscitation:.

- Rheumatic heart disease:

8. Using the following word analysis, write the combining forms, suffix, or prefix related to the cardiovascular system that matches its definition in the space provided to the left of the definition. There may be more than one-word element that matches a definition.

\begin{tabular}{|c|c|c|c|}
\hline Combining & Forms & Suffixes & Prefixes \\
\hline aort/o & coron/o & -cardia & brady- \\
\hline $\begin{array}{l}\text { arteri/o } \\
\text { atri/o } \\
\text { cardi/o }\end{array}$ & $\begin{array}{l}\text { hem/o } \\
\text { hemat/o } \\
\text { my/o }\end{array}$ & $\begin{array}{l}\text {-stenosis } \\
\text {-pathy } \\
\text {-emia }\end{array}$ & $\begin{array}{l}\text { tachy- } \\
\text { peri- }\end{array}$ \\
\hline
\end{tabular}

Word Element Word Analysis

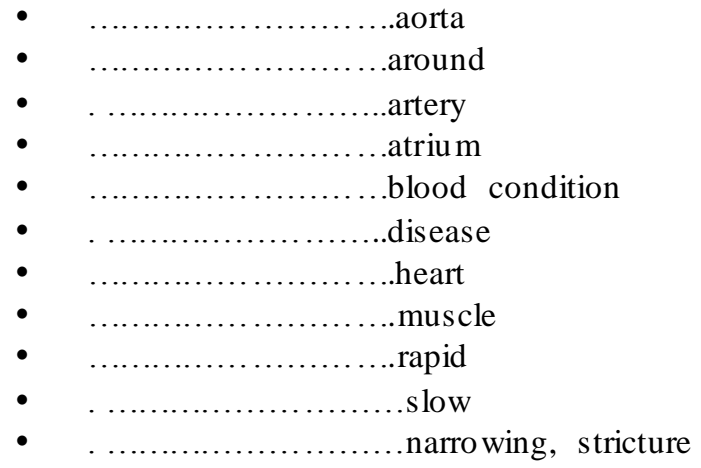

9. Decipher the medical terms using word analysis (prefixes, roots, combining vowel, suffixes ) and give their meanings:

- Pericarditis Dysrhythmia Echocardiography Sonography

- Cardiologist Arteriospasm Arteriosclerosis Aortopathy

- Phleborrhaphy Tachypnea Bradycardia Cardiomegaly

Appendix 4. Assessment Tools from Appendix 1, 2 and 3 (Results of the First and Second Group)

Group one Group two

Group one Group two

Group one Group two

Group one Group two

Group one Group two
Time

from half an houruntil hour more than hour

Marks

$\mathrm{A}(20)-\mathrm{B}(30)$

$\mathrm{A}(12)-\mathrm{B}(18)-\mathrm{C}(13)-\mathrm{D}(7)$

Lack of medical knowledge in technical terms $\mathrm{A}(10)-\mathrm{B}(40)$

Group two $\quad \mathrm{A}(20)-\mathrm{B}(12)-\mathrm{C}(13)-\mathrm{D}(5)$

Interpreting big health data

$\mathrm{A}(30)-\mathrm{B}(20)$

$\mathrm{B}(15)-\mathrm{C}(25)-\mathrm{D}(10)$

Analyze medical terms

$\mathrm{A}(20)-\mathrm{B}(25)-\mathrm{C}(5)$

$\mathrm{B}(10)-\mathrm{C}(25)-\mathrm{D}(15)$

Determine meaning

$\mathrm{A}(25)-\mathrm{B}(20)-\mathrm{C}(5)$

$\mathrm{A}(10)-\mathrm{B}(22)-\mathrm{C}(6)-\mathrm{D}(12)$ 
Give the meanings of a beginning set of roots, combining forms, suffixes and prefixes

Group one $\mathrm{A}(30)-\mathrm{B}(20)$

Group two $\mathrm{A}(9)-\mathrm{B}(16)-\mathrm{C}(14)-\mathrm{D}(11)$

Name the referents of abbreviations

Group one $\mathrm{A}(30)-\mathrm{B}(20)$

Group two $\quad \mathrm{A}(15)-\mathrm{B}(10)-\mathrm{C}(12)-\mathrm{D}(13)$

Skills

Group one meaningful learning, critical thinking and problem solving

Group two learning and memorizing

$\mathrm{A}=10$ (correct ans wers, excellent) $\mathrm{B}=7$ (correct answers, good) $\mathrm{C}=5$ (correct answers, average) $\mathrm{D}=2$ (correct answers, bad) and () number of learners in both groups

\section{REFERENCES}

[1] Ausubel, D.P., Educational psychology: a cognitive view, Holt, Rinehart and Winston, New York, 1968.

[2] Ausubel, D.P, Novak JD, Hanesian, H., Educational psychology: a cognitive view (2nd edition). Holt, Rinehart and Winston, New York, 1978.

[3] Asan, A., Concept mapping in science class: a case study of fifth grade students, Journal of Educational Technology \& Society, Retrieved June 2, 2019, from https://www.learntec hlib.org/p/75104/, 10(1), 186-195, 2007.

[4] Atay, S., \& Karabacak ,U., Care plans using concept maps and their effects on the critical thinking dispositions of nursing students, Int J Nurs Pract,18(3),233-239,2012.

[5] Buntting, C., Coll, R. K., Campbell, A., Student views of concept mapping use in introductory tertiary biology classes, International Journal of Science and Mathematics Education, 4, 641-668,2006.

[6] Bieliaieva, O.M., Lysanets, Y.V., Znamenska, I.V., Rozhenko, I.V., Nikolaieva, N.M., Terminological collocations in medical Latin and English: a comparative study,Wiad Lek, 70(1), 139-43,2017.

[7] Betty, D.J., Comprehensive medical terminology (4 th edition), Delmar Cengage learning, USA, 2011.

[8] Betsy, J.S., Medical terminology and anatomy for ICD-10 Coding, St. Louis, Missouri Mosby, Elsevier.,2012.

[9] Baig M., Tariq S., Rehman R., Ali S., Gazzaz Z.J., Concept mapping improves academic performance in problem solving questions in Biochemistry subject, Pak J Med Sci, $32,801-805,2016$.

[10] Chularut ,P., \& DeBacker ,T.K., The influence of concept mapping on achievement, self-regulation, and self-efficacy in students of English as a second language, Contemporary Educational Psychology, 29(3), 248-263,2004.

[11] Cañas,A.J., \& Carvalho, M., Concept maps and AI: An unlikely marriage?, In: SBIE 2004, Proceedings of the
Simpósio Brasileiro de Informática Edu cativa SBC,Manaus, Brasil,:Sociedade Brasileira de Computacao,2004.

[12] Costa, J.V., Rocha, F.E., Favero, E.L., Linking phrases in concept maps: A study on the nature of inclusivity, In A.J. Canas, J. D. Novak, \& F.M. Gonzalez (Editors), concept maps: theory, methodology, technology, Universidad Publica de Navarra, Pampalona, Spain, 2004.

[13] Chabeli, M., Concept-mapping as a teaching method to facilitate critical thinking in nursing education: A review of the literature, Journal of Interdisciplinary Health Sciences, 15, 1-7, 2010.

[14] Cutrer, W.B., Castro, D., Roy, K.M., Turner, T.L., Use of an expert concept map as an advance organizer to improve understanding of respiratory failure. Med Teach, 33(12), 1018-1026, 2011.

[15] Carol, L. S., Medical terminology for health professions (7th edition), Delmar, Cengage Learning, 2013.

[16] Cañas, A. J., Novak, J. D., \& Reiska, P., Freedom vs. Restriction of content and structure during concept Mapping-possibilities and limitations for construction and Assessment. In A. J. Cañas, J. D. Novak, \& J. Vanhear (Eds.), Concept Maps: Theory, methodology, technology Proceedings of the fifth international conference on Concept mapping (Vol. 2, pp. 247-257), Valletta, Malta: University of Malta,2012.

[17] Cohen, B.J., \& DePetris, A., Medical terminology: an illustrated guide (7th edition), Baltimore: Lippincot Williams and Wilkins, Wolters Kluwer health, 2013.

[18] Cañas, A. J., Novak, J. D., \& Reiska, P., How good is my concept map? Am I a good Cmapper? Knowledge Management \& E-Learning: An International Journal (KM\&EL), 7(1), 6-19, 2015.

[19] Cañas, A.J.; Reiska, P.; Möllits, A., Developinghigher-order thinking skills with concept mapping: A Case of pedago gic frailty, Knowl. Manag. E-Learn, 9, 348-365, 2017.

[20] Daley, B., Learning and professional practice: a study of four professions, Adult Education Quarterly, 52, 1, 39-54, 2001.

[21] Dzuganova, B., A brief outline of the development of medical English, Bratisl Lek Listy, 103 (6), 223-227, 2002.

[22] Dong,R., Yang ,X., Xing ,B., Zou ,Z., Zheng ,Z., Xie ,X., Zhu ,J., Chen ,L., Zhou,H., Use of concept maps topromote electrocardiogram diagnosis learning in undergraduate medical students .Int J Clin Exp Med,8(5),7794-7801, 2015.

[23] Davi-Ellen, C., The language of medicine (10 edition), Elsevier Mosby, Canada, 2014.

[24] Drareni, N., Using concept mapping through problem-based learning to facilitate lifelong knowledge of risk factors for cardiovascular diseases: case university of Algiers, Journal of Modern Education Review, 8(6), 458-468, 2018.

[25] Drareni, N., Structuring interdisciplinary learning using TBL through PBL in cardiovascular diseases case: university of Algiers, PUPIL: International Journal of Teaching, Education and Learning, 3(2), 29-46, 2019.

[26] Ellermann,CR. , Kataoka,_Y.M.R., Wong, L.C., Logic models used to enhance critical thinking, Journal of nurse educator,45(6), 220-227,2006. 
[27] Erdogan, Y., Paper-based and computer-based concept mappings: the effects on computer achievement, computer anxiety and computer attitude, British Journal of Educational Technology, 40,821-836, 2009.

[28] Fisher, K., Semantic networking: the new kid on the block, Journal of Research in Science Teaching, 27(10), 1001-1018, 1990.

[29] Fisher, K.M., SemNet ${ }^{\circledR}$ Semantic Networking. In K. M. Fisher, J. H. Wandersee \& D. E. Moody (Eds.), mapping biology knowledge (pp. 143-165), Dordrecht, the Netherlands: Kluwer Academic Publishers, 2000.

[30] Gerstner, S. \& Bogner, F. X., Concept map structure, gender and teaching methods: an investigation of students' science learning, Educational Research, 51, 425-438, 2009.

[31] Gylys, B.A., \& Masters R. M., A programmed learning approach by body system fifth edition, F. A. Davis Company Philadelpgia, 2014.

[32] Harpaz ,I., Balik, C., Ehrenfeld, M., Concept mapping: an educational strategy for advanced nursing education, Nursing Forum, 39(2),27-30,36,2004.

[33] Hay, D.B., \& Kinchin IM., Using concept maps to reveal conceptual typologies, Education and Training. 48 (2-3), 127-142, 2006.

[34] Hay, D., Kinchin, I., Lygo-Baker, S., Making learning visible: the role of concept mapping in higher education, Studies in Higher Education, 33(3), 295-306, 2008.

[35] Kremer, R., The design of a concept mapping environment for knowledge acquisition and knowled ge representation. KAW'95: Proceedings of the 9th International Knowledge Acquisition. Banff, Canada, 1995.

[36] Kinchin, I.M., Hay, D.B., Adams, A., How a qualitative approach to concept map analysis can be used to aid learning by illustrating patterns of conceptual development, Educ Res,42 (1),43-57,2000.

[37] Kumar, S., Dee, F., KumarManoj, \& Rizwaan, M., Impact of teaching through concept mapping on Achievement in social studies' Kumar, R., Velan, G. (2011), Benefits of testable concept maps for learning about pathogenesis of disease, Teach Learn Med, 23,137- 143,2013.

[38] KumarManoj, \& Rizwaan, M., Impact of teaching through concept mapping on Achievement in social studies components, International Indexed \& Refereed Research Journal, 4(46),54-57,2013.

[39] Kaddoura, M., Van-Dyke, O., Yang, Q. , Impact of a concept map teaching approach on nursing students' critical thinking skills, Nurs Health Sci, 18(3), 350-354, 2016.

[40] Lysanets, Y.V., \& Bieliaieva, O.M., The use of Latin terminology in medical case reports: quantitative, structural, and thematic analysis, J Med Case Rep, 12(1), 45, 2018.

[41] Maas, J., \& Leauby, B.A., Concept mapping: exploring its value as a meanin gful learning tool in accounting education, Global Perspectives of Accounting Education, 2(1), 75-98, 2005.

[42] Maas, J., \& Burgess-Wilkerson, B., The Development of a student concept mapping guide for business communications, The International Journal of
Interdisciplinary Social Sciences, 6(5), 215-226, 2012.

[43] Novak, J.D., \& Gowin, D.B., Learning how to learn, New York: Cambridge: Cambridge University Press, 1984.

[44] Novak, J.D., Concept mapping: A useful tool for science education, Journal of research in science teaching, 27(10), 937-49, 1990.

[45] Novak, J.D., Concept maps and vee diagrams: two metacognitive tools to facilitate Meaningful Learning, Instructional Science, Retrieved November 2, 2019, from https://doi.org/10.1007/BF00377984, 19(1), 29-52, 1990.

[46] Novak, J.D., Learning, creating, and using knowledge: concept maps as facilitative tools in schools and corporations, Mahwah, NJ: Lawrence Erlbaum Associates, Inc, 1998.

[47] Novak, J.D., Meaningful learning: the essential factor for conceptual change in limited or in appropriate propositional hierarchies leading to empowerment of learners, Science Education, 86 (4), 31- 557, 2002.

[48] Novak, J.D., The promise of new ideas and new technology for improving teaching and Learning, Cell Biol Educ, 2,122-132, 2003 .

[49] Novak, J.D, \& Canas, A.J., The theory underlying concept maps and how to construct them, Technical Report IHMC Camp Tools 2006-01, Pensacola, FL: Institute for Human and Machine Cognition. Retrieved January 10, 2019, fromhttp://cmap.ihmc.us/Publications/ResearchPapers/The ory Underly ingConceptM aps.pdf, 2006.

[50] Novak, J.D, \& Canas, A.J., The origins of the concept mapping tool and the continuing evolution of the tool, Palgrave Macmillan, 5,175-184, 2006.

[51] Nesbit, J.C., \& Adesope, O.O., Learning with concept and knowledge maps: A meta-analysis, Review of Educational Research, 76(3), 413-448, 2006.

[52] Novak, J. D., \& Cañas, A. J., The theory underlying concept maps and how to construct and use them, IHMC Cmap Tools. Retrieved January 10, 2019, from Institute for Human and Machine Cognition (IHMC): https://cmap.ihm c.us/docs/theory-of-concept-maps, 2008.

[53] Novak, J.D., Learning, creating, and using knowledge: concept maps as facilitative Tools in schools and corporations, Journal of e-Learning and Knowledge Society, 6(3), 21-30, 2010.

[54] Oppl, S., \& Stary, C., Designing digital work concepts and methods for human-centered digitization, Palgrave Macmillan, Cham: Switzerland, 325-423, 2019.

[55] Pintoi A.J., \& Zeitz, H.J., Concept mapping: a strategy for promoting meaningful learning in medical education, Med Teach, 19 (2), 114-21, 1997.

[56] Pudelko, B., Young, M., Vincent-Lamarre, P., Charlin, B., Mapping as a learning strategy in health professions education: a critical analysis, Published in Medical Education, 46(12), 1215-1225, 2012.

[57] Ruiz-Primo, M.A., \& Shavelson, R.J., Problems and issues in the use of concept maps in science assessment, Journal of Research in Science Teaching, 33(6), 569-600, 1996. 
[58] Rendas, A.B., Fonseca, M., Pinto P.R, toward meaningful learning in undergraduate medical education using concept maps in a PBL physiopathology course, Advances in Phy siology Education, 30 (1), 23-29,2006.

[59] Romero, C., Cazorla, M., Buzón, O. , Meaningful learning using concept maps as a learning strategy, J. Technol. Sci. Educ, 7, 313-332,2017.

[60] Sowa, J., Conceptual structures: information processing in mind and machine, Addison-Wesley Publishing Company, USA, 1984.

[61] Susan, J., Likert scales: how to (ab) use them, Med Educ, 38(12), 1217-1218, 2005.

[62] Sowa, J., Concept mapping, talk presented at the AERA conference, San Francisco, Retrieved September 10, 2019, from http://www.jfsowa.com/talks/cmap ping.pdf, 2019.

[63] Sharma, S. Effect of concept mapping strategy on the learning outcome in relation to Intelligence and study habits, International Multidisciplinary e-Journal, 1(7), 44-52,2012.

[64] Santos, V.D., Souza, É.F.D., Felizaro, K.R., Vijaykumar, N.L., Analyzing the use of concept maps in computer science: a systematic mapping study, Informatics in Education: Vilnius University, 16(2), 257-288, 2017.

[65] Trepagnier, B., Mapping sociological concepts, Teaching Sociology, 30(1), 108-119, 2002.

[66] Trowbridge, J.E., Wandersee, J.H., Theory-driven graphic organizers, In Mintzes, J. J., Wandersee JH, Novak JD (Eds.), teaching science for understanding: A human constructivist view (pp. 95-131), New York Elsevier Academic press, 2005.

[67] Torre, D.M., Daley, B., Tracy, Stark-Schweitzer, Singh Siddartha, Jenny Petkova, Monica Ziebert., A qualitative evaluation of medical student learning with concept maps, Medical Teacher, 29(9-10), 949-955,2007.

[68] Wilner, L.K., \&Feinstein-Whittaker M., Medically speaking rules (First edition), Owings Mills, MD: Successfully Speaking, 2007.

[69] Yaowalak J., The Effectiveness of using concept mapping to Improve primary medical care nursing competencies among Fourth year, Faculty of Nursing Science, Assumption University, Bangkok, Thailand, Assumption University Nursing Students, AU J.T. 9(2): 111-120,2005.

[70] Zhang, F., \& Wang, S., The present situation and reflections of medical college students' oral English, Northwest Medical Education, Vol. 14, No.5: 578-579, 2006. 